This is the peer-reviewed version of the article

Lukić, M. J., Veselinović, L., Stevanović, M., Nunić, J., Dražič, G., Marković, S., Uskoković, D. 2014,

"Hydroxyapatite nanopowders prepared in the presence of zirconium ions", Materials Letters, vol. 122, pp. 296-300, http://dx.doi.org/10.1016/j.matlet.2014.02.072.

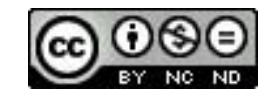

This work is licensed under

Creative Commons - Attribution-Noncommercial-NoDerivative Works 3.0 Serbia 


\title{
Hydroxyapatite nanopowders prepared in the presence of zirconium ions
}

M. J. Lukić* ${ }^{1}$, Lj. Veselinović ${ }^{1}$ M. Stevanović ${ }^{1}$ J. Nunić ${ }^{2}$, G. Dražič, ${ }^{3}$ S. Marković ${ }^{1}$ D. Uskoković $^{1}$

${ }^{1}$ Institute of Technical Sciences of the Serbian Academy of Sciences and Arts, Belgrade, Serbia

${ }^{2}$ Department of Genetic Toxicology and Cancer Biology, National Institute of Biology, Ljubljana, Slovenia

${ }^{3}$ Laboratory for Materials Chemistry, National Institute of Chemistry, Ljubljana, Slovenia *corresponding author: miodrag.lukic@itn.sanu.ac.rs

\begin{abstract}
Hydroxyapatite nanopowders were prepared in the presence of different concentrations of zirconium ions. Such crystallization conditions yielded significantly reduced particle size and increased specific surface area. Cell viability and oxidative stress studies showed that biocompatibility was not impaired when compared to pure hydroxyapatite. Non-isothermal sintering implied the possibility for suppressing the reaction between hydroxyapatite and zirconia by limiting it to only calcium phosphates. Stress-induced transformation of tetragonal to monoclinic is facilitated by total hydroxyapatite to $\beta$-tricalcium phosphate phase transformation.
\end{abstract}

Keywords: biomaterials, bioceramics, FTIR, sintering

\section{Introduction}

The improvement of material properties without negatively affecting the biological response is a permanently targeted issue concerning bioceramics. Hydroxyapatite (HAp) is a bioactive material 
and one of the most suitable ceramics for bone and dental tissue reconstruction, but still lacks adequate mechanical properties. However, zirconia $\left(\mathrm{ZrO}_{2}\right)$ offers good mechanical response, but has a disadvantage of poor bonding to host tissue. Their composites are quite promising, though, offering many potential biological and structural advantages. $\mathrm{HAp} / \mathrm{ZrO}_{2}$ composites are usually prepared by physical mixing or colloidal dispersions of $\mathrm{ZrO}_{2}$ with $\mathrm{HAp}$ [1]. The addition of other phases to HAp influences its bioactivity and phase stability during sintering [2]. Procedures that reduce the amount of reinforcing agents have already been investigated [3]. Also, pressureless densification of $\mathrm{HAp} / \mathrm{ZrO}_{2}$ is difficult because of the mismatch in thermal expansion coefficients and requires field-assisted sintering techniques and tetragonal $\mathrm{ZrO}_{2}\left(\mathrm{t}-\mathrm{ZrO}_{2}\right)$ stabilization since there is a tendency to reactions between $\mathrm{HAp}$ and $\mathrm{ZrO}_{2}[4,5]$.

In this study, the preparation of HAp nanopowders in the presence of different amounts of zirconium ions was performed under reflux conditions. Detailed structural and chemical characterizations were performed, while biocompatibility was determined in cytotoxicity and oxidative stress studies. Non-isothermal sintering was performed up to $1300{ }^{\circ} \mathrm{C}$ and the results were correlated with the phase composition.

\section{Materials and methods}

Chemical precipitation has been performed with following precursors: calcium nitrate tetrahydrate, $\mathrm{Ca}\left(\mathrm{NO}_{3}\right)_{2} \cdot 4 \mathrm{H}_{2} \mathrm{O}$, (Fluka Analytical, Germany), zyrconyl chloride octahydrate, $\mathrm{ZrOCl}_{2} \cdot 8 \mathrm{H}_{2} \mathrm{O}$, (The British Drug Houses Ltd., United Kingdom) and ammonium dihydrogen phosphate, $\mathrm{NH}_{4} \mathrm{H}_{2} \mathrm{PO}_{4}$, (Zorka Šabac, Serbia). Concentrations were adjusted to retain $(\mathrm{Ca}+\mathrm{Zr}) / \mathrm{P}$ molar ratio of 1.67 for different amounts of zirconium $(0,1,5$ and 10 at.\% with respect to $\mathrm{Ca})$, denoted as HAp-X $(\mathrm{X}=0,1,5,10)$, respectively. Reactants were dissolved in $80 \mathrm{ml}$ of distilled water each and heated to $70{ }^{\circ} \mathrm{C}$. The solutions of calcium and zirconium ions were mixed, followed by the addition of a phosphate solution and precipitation by the dropwise addition of 10 $\mathrm{ml}$ of $\mathrm{NH}_{4} \mathrm{OH}$ to reach $\mathrm{pH} 11$. The reaction batch $(250 \mathrm{ml})$, enclosed in reflux conditions to 
provide constant $\mathrm{pH}$ in the presence of small amount of $\mathrm{NH}_{4} \mathrm{OH}$, was effectively stirred for $3 \mathrm{~h}$ at $70{ }^{\circ} \mathrm{C}$, with afterward ageing, washing out to $\mathrm{pH} 7$ and drying. The phase analysis was carried out using X-ray diffraction (Philips PW-1050). The FTIR measurement was performed in the spectral range of $400-4000 \mathrm{~cm}^{-1}$ (BOMEM, Hartmann\& Braun). Particle size and morphology were investigated using transmission electron microscopy (TEM, JEOL 2100); elemental mapping was performed by EDXS analysis (JEOL ARM 200 CF equipped with JEOL centurion 100). The specific surface area (SSA) was measured by Brunauer-Emmett-Teller (BET) technique with $\mathrm{N}_{2}$ adsorption-desorption isotherms at $-195.8^{\circ} \mathrm{C}$ (Micromeritics Gemini 2370 V5).

For determination of the biological response we used HepG2 cells, which were obtained from the European Collection of Cell Cultures (UK) and were grown as described previously [6]. The cytotoxicity was determined with 3-(4,5-dimethylthiazol-2-yl)-2,5-diphenyltetrazolium bromide (MTT) according to Mosmann [7], with minor modifications [6]. The HepG2 cells were seeded onto 96-well microplates (Nunc, Naperville IL, USA) at a density of 40000 cells $/ \mathrm{ml}$ and incubated for $20 \mathrm{~h}$ at $37^{\circ} \mathrm{C}$ to attach. The medium was replaced by fresh medium containing 0 , $0.00001,0.0001,0.001,0.01$ and $0.1 \%(\mathrm{w} / \mathrm{v})$ of HAp-X $(\mathrm{X}=0,1,5,10)$ samples and incubated for $24 \mathrm{~h}$. In each experiment a negative control (non-treated cells) was included. The protocol was continued as described previously [6]. Cell survival was determined by comparing the optical density of the wells containing the treated cells with those of the negative control.

The formation of intracellular reactive oxygen species (ROS) was measured spectrophotometrically using the fluorescent probe DCFH-DA [8], with minor modifications [6]. The HepG2 cells were seeded at a density of 75000 cells/ml into 96-well, black microplates (Nunc, Naperville IL, USA) in five replicates and incubated for $20 \mathrm{~h}$ at $37^{\circ} \mathrm{C}$ to attach. After that, the cells were incubated with $20 \mathrm{mM}$ DCFH-DA for $30 \mathrm{~min}$, then DCFH-DA was removed, and cells were washed out with PBS and treated with concentrations $0,0.00001,0.0001,0.001,0.01$ and $0.1 \%(\mathrm{v} / \mathrm{v})$ of HAp-X $(\mathrm{X}=0,1,5,10)$ samples. Negative control (non-treated cells) and 
positive control ( $0.5 \mathrm{mM}$ tert-butyl hydroperoxide treated) were always included. The protocol was continued as described previously [6].

The powders were uniaxially pressed under $100 \mathrm{MPa}$. Non-isothermal sintering was performed to $1300{ }^{\circ} \mathrm{C}$ in a heating microscope (New Heating Microscope EM201, Hesse Instruments) with the heating rate of $10{ }^{\circ} \mathrm{C} / \mathrm{min}$.

\section{Results and discussion}

XRD patterns of the prepared materials, Fig. 1a, showed the reflections characteristic for HAp. The only difference among these samples was the diffuse scattering in $20-40^{\circ} 2 \theta$ range for HAp10 sample, which could originate from $\mathrm{ZrO}_{2}$ phase [9].

FTIR spectra, Fig. 1b, of the synthesized powders were almost identical, showing typical apatite phosphate $\left(\mathrm{PO}_{4}^{3-}\right)$ modes at: $470 \mathrm{~cm}^{-1}$ ( $v 2$ bending vibration), 564 and $602 \mathrm{~cm}^{-1}$ ( $v 4$ bending vibration), $962 \mathrm{~cm}^{-1}$ ( $\mathrm{v} 1 \mathrm{symmetric}$ stretching vibration), and in the $1000-1150 \mathrm{~cm}^{-1}$ region (v3 asymmetric stretching mode). The bands at 1637 and in the $3000-3650 \mathrm{~cm}^{-1}$ range are attributed to associated water. The $\mathrm{O}-\mathrm{H}$ libration and stretching modes appeared at 632 and 3570 $\mathrm{cm}^{-1}$, respectively. Vibrational bands at $669,875 \mathrm{~cm}^{-1}$ and in the $1450-1500 \mathrm{~cm}^{-1}$ region are attributed to $v 4, v 2$ and $v 3$ stretching modes of incorporated carbonates, respectively.

Deconvolution of $400-750 \mathrm{~cm}^{-1}$ spectral region of HAp-5 and HAp-10 yielded three more peaks centered at 425,525 , and $580 \mathrm{~cm}^{-1}$ that could be attributed to $\mathrm{Zr}-\mathrm{O}$ stretching mode [10], suggesting the formation of $\mathrm{ZrO}_{2}$ phase and the existence of $\mathrm{HAp} / \mathrm{ZrO}_{2}$ composite.

The results of TEM analysis, shown in Fig. 2, revealed that all the prepared powders possessed uniform particles. However, with higher concentrations, both the particle size and their aspect ratio changed. The particles of HAp- 0 were $150 \mathrm{~nm}$ long and around $20 \mathrm{~nm}$ wide, while those of HAp-10 had the length of around $45 \mathrm{~nm}$ and the width of less than $10 \mathrm{~nm}$, with more rounded morphology. The EDXS analysis showed that $\mathrm{ZrO}_{2}$ is uniformly dispersed within the 
samples; slight aggregation was observed for higher initial concentrations of zirconium. The size of zirconia particulates is around $25 \mathrm{~nm}$, with rounded morphology. Reduction of the particle size led to an increase of SSA, being 74, 73, 126, and $137 \mathrm{~m}^{2} / \mathrm{g}$ for HAp-X $(\mathrm{X}=0,1,5,10)$ samples, respectively.

Biocompatibility studies of the prepared nanopowders confirmed that the initial properties of pure HAp were not impaired with the addition of zirconium ions. The cytotoxicity determined by MTT assay after $24 \mathrm{~h}$ exposure, Fig. 3a, revealed that all samples have concentration-dependent, but comparable levels of cytotoxicity, independent on the amount of zirconium ions. On the other side, measurements of the oxidative stress induced in Hep G2 cells, Fig. 3b, showed that all the samples after $5 \mathrm{~h}$ induced favourable response, without significant generation of ROS. Only the highest concentration showed the ROS increase.

From non-isothermal sintering studies, Fig. 4a, very different sintering behavior was found and correlated to the phase composition, Fig. 4b. HAp-0 sample sintered around $1100{ }^{\circ} \mathrm{C}$ remained pure HAp phase due to stoichiometric $\mathrm{Ca} / \mathrm{P}$ ratio. HAp-1 sample had a lower bulk density and the dominant presence of HAp phase with a small amount of $\beta$-tricalcium phosphate ( $\beta$-TCP) phase and the appearance of $\mathrm{t}-\mathrm{ZrO}_{2}$. The lower density is explained by densification suppression in the presence of TCP phases with lower theoretical densities $(2.86,3.07$ and 3.16 $\mathrm{gcm}^{-3}$ for $\alpha$-TCP, $\beta$-TCP and HAp, respectively). HAp-5 showed better densification comparing to HAp-1. Phase composition analysis revealed a higher amount of $\mathrm{t}-\mathrm{ZrO}_{2}$ phase in co-existence with HAp and $\alpha$-TCP» $\beta$-TCP phases. The fact that HAp- 1 and HAp-5 retained $\mathrm{t}-\mathrm{ZrO}_{2}$ could be suitable for formation of $\mathrm{BCP} / \mathrm{ZrO}_{2}$ [11]. The formation of cubic zirconia and/or calcium zirconate above $1200^{\circ} \mathrm{C}[12]$, which could inhibit the toughening mechanism through transformation of $\mathrm{t}-\mathrm{ZrO}_{2}$ to $\mathrm{m}-\mathrm{ZrO}_{2}$, was not observed. Since HAp-1 and HAp-5 are basically Cadeficient HAp, they decompose above $700{ }^{\circ} \mathrm{C}$ and prevent the reaction between $\mathrm{HAp}$ and $\mathrm{t}-\mathrm{ZrO}_{2}$. HAp-10 sample showed two distinct sintering regions: enhanced sintering up to $900{ }^{\circ} \mathrm{C}$ and subsequent retardation from 900 to $1100{ }^{\circ} \mathrm{C}$. Biodegradable $\beta$-TCP appeared as the only 
calcium phosphate phase, while $\mathrm{m}-\mathrm{ZrO}_{2}$ was the dominant phase compared to $\mathrm{t}-\mathrm{ZrO}_{2}$. The explanation for such a phase composition is related to the initial $\mathrm{Ca} / \mathrm{P}$ ratio of $\mathrm{HAp}-10$ sample, being 1.5, which yields total decomposition of HAp to $\beta$-TCP; that is accompanied with sudden volume expansion, which could provoke stress-induced transformation of $\mathrm{t}-\mathrm{ZrO}_{2}$ to $\mathrm{m}-\mathrm{ZrO}_{2}$. This is expressed as retardation in the sintering curves, Fig. 4a. It is important to observe that HAp-10 starts sintering at $800{ }^{\circ} \mathrm{C}$ due to $\mathrm{Ca}^{2+}$ vacancies in HAp crystal lattice. As a suggestion for the further research, phase transformation stresses could be avoided in water vapor atmosphere, and the final system could retain $\mathrm{t}-\mathrm{ZrO}_{2}$, susceptible to transformation toughening under mechanical loading.

\section{Conclusions}

Hydroxyapatite nanopowders were successfully prepared in the presence of zirconium ions. With zirconium addition, the particle morphology became more rounded and the particle size significantly decreased, from 150 to $45 \mathrm{~nm}$ in length and from 20 to $10 \mathrm{~nm}$ in width, yielding the doubling of SSA. Biocompatibility was not altered compared to pure HAp. Sintering studies showed that the phase composition could be tailored by the appropriate choice of zirconium amount and that HAp-1 and HAp-5 samples exhibited the presence of only $\mathrm{t}-\mathrm{ZrO}_{2}$ after nonisothermal sintering. For HAp-10 sample, it was shown that the complete phase transformation from HAp to $\beta$-TCP provoked stress-induced transformation of $\mathrm{t}-\mathrm{ZrO}_{2}$ to $\mathrm{m}-\mathrm{ZrO}_{2}$. Using $\mathrm{HAp}$ with $\mathrm{Ca} / \mathrm{P}$ ratio $1.67 \leq \mathrm{x} \leq 1.5$, the reaction between $\mathrm{HAp}$ and $\mathrm{ZrO}_{2}$ is suppressed by providing an alternative, less energy-consuming pathway of Ca-deficient HAp decomposition, confining the reaction only to the calcium phosphate phase. 


\section{Acknowledgements}

This study was supported by the Ministry of Education, Science and Technological Development of the Republic of Serbia under grant no. III45004. The authors are thankful to Dr. Ines Bračko for TEM measurements.

\section{References}

[1] Sung Y-M, Shin Y-K, Ryu J-J. Preparation of hydroxyapatite/zirconia bioceramic nanocomposites for orthopaedic and dental prosthesis applications. Nanotechnology 2007;18:065602.

[2] Sultana R, Yang J, Hu X. Deposition of micro-porous hydroxyapatite/tri-calcium phosphate coating on zirconia-based substrate. J Am Ceram Soc 2012;95:1212-5.

[3] Ahn ES, Gleason NJ, Ying JY. The Effect of zirconia reinforcing agents on the microstructure and mechanical properties of hydroxyapatite-based nanocomposites $\mathrm{J}$ Am Ceram Soc 2005;88:3374-9.

[4] Ergun C. Enhanced phase stability in hydroxylapatite/zirconia composites with hot isostatic pressing. Ceram Int 2011;37:935-42.

[5] Gergely G, Sahin FC, Göller G, Yücel O, Balázsi C. Microstructural and mechanical investigation of hydroxyapatite-zirconia nanocomposites prepared by spark plasma sintering. J Eur Ceram Soc 2013;33:2313-19.

[6] Petković J, Žegura B, Stevanović M, Drnovšek N, Uskoković D, Novak S, Filipič M. DNA damage and alterations in expression of DNA damage responsive genes induced by $\mathrm{TiO}_{2}$ nanoparticles in human hepatoma HepG2 cells. Nanotoxicology 2011;5:341-53.

[7] Mosmann T. Rapid colorimetric assay for cellular growth and survival: Application to proliferation and cytotoxicity assays. J Immunol Methods 1983;65:55-63. 
[8] Osseni R, Debbasch C, Christen M-O, Rat P, Warnet J-M. Tacrine-induced Reactive Oxygen Species in a Human Liver Cell Line: The Role of Anethole Dithiolethione as a Scavenger. Toxicol In Vitro 1999;13:683-8.

[9] Chaudhry AA, Yan H, Viola G, Reece MJ, Knowles JC, Gong K, Rehman I, Darr JA. Phase stability and rapid consolidation of hydroxyapatite-zirconia nano-coprecipitates made using continuous hydrothermal flow synthesis. J Biomater Appl 2012;27:79-90.

[10] Manivasakan P, Rajendran V, Rauta PR, Sahu BB, Panda BK. Synthesis of monoclinic and cubic $\mathrm{ZrO}_{2}$ nanoparticles from zircon. J Am Ceram Soc 2011;94:1410-20.

[11] Kim M, Franco RA, Lee B-T. Synthesis of functional gradient $\mathrm{BCP} / \mathrm{ZrO}_{2}$ bone substitutes using $\mathrm{ZrO}_{2}$ and BCP nanopowders. J Eur Ceram Soc 2011;31:1541-8.

[12] Evis Z, Usta M, Kutbay I. Improvement in sinterability and phase stability of hydroxyapatite and partially stabilized zirconia composites. J Eur Ceram Soc 2009;29:621-8.

\section{Figure captions}

Fig. 1 a) XRD patterns and b) FTIR spectra of precipitated powders.

Fig. 2 TEM micrographs of prepared nanopowders; EDXS mapping of $\mathrm{Zr}$ density, and $\mathrm{Ca}$ and $\mathrm{Zr}$ concentration.

Fig. 3 a) MTT assay and b) ROS study of prepared nanopowders.

Fig. 4 a) Non-isothermal sintering curves to $1300^{\circ} \mathrm{C}$ and b) corresponding XRD patterns. 
Fig. 1.
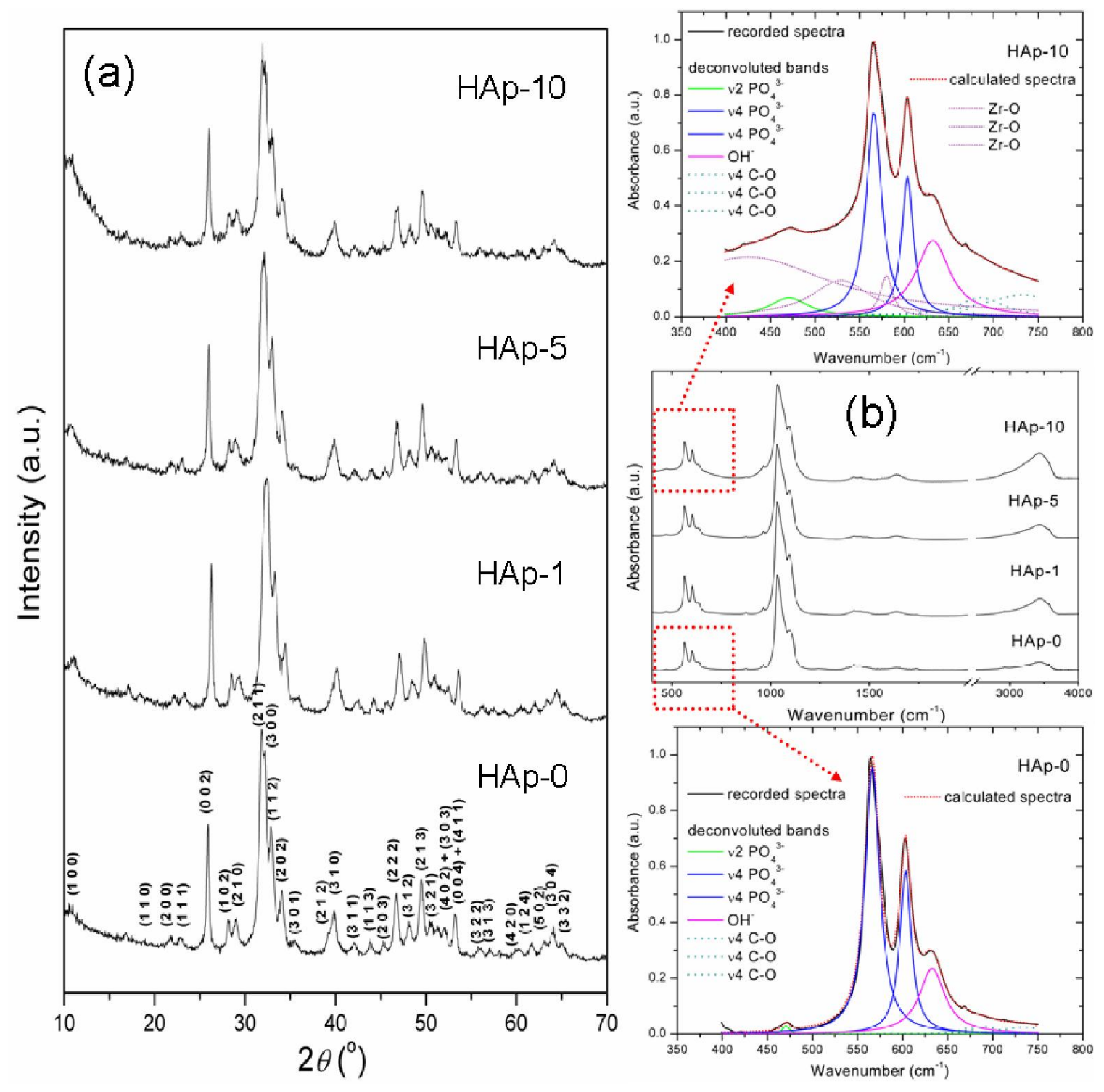
Fig. 2.

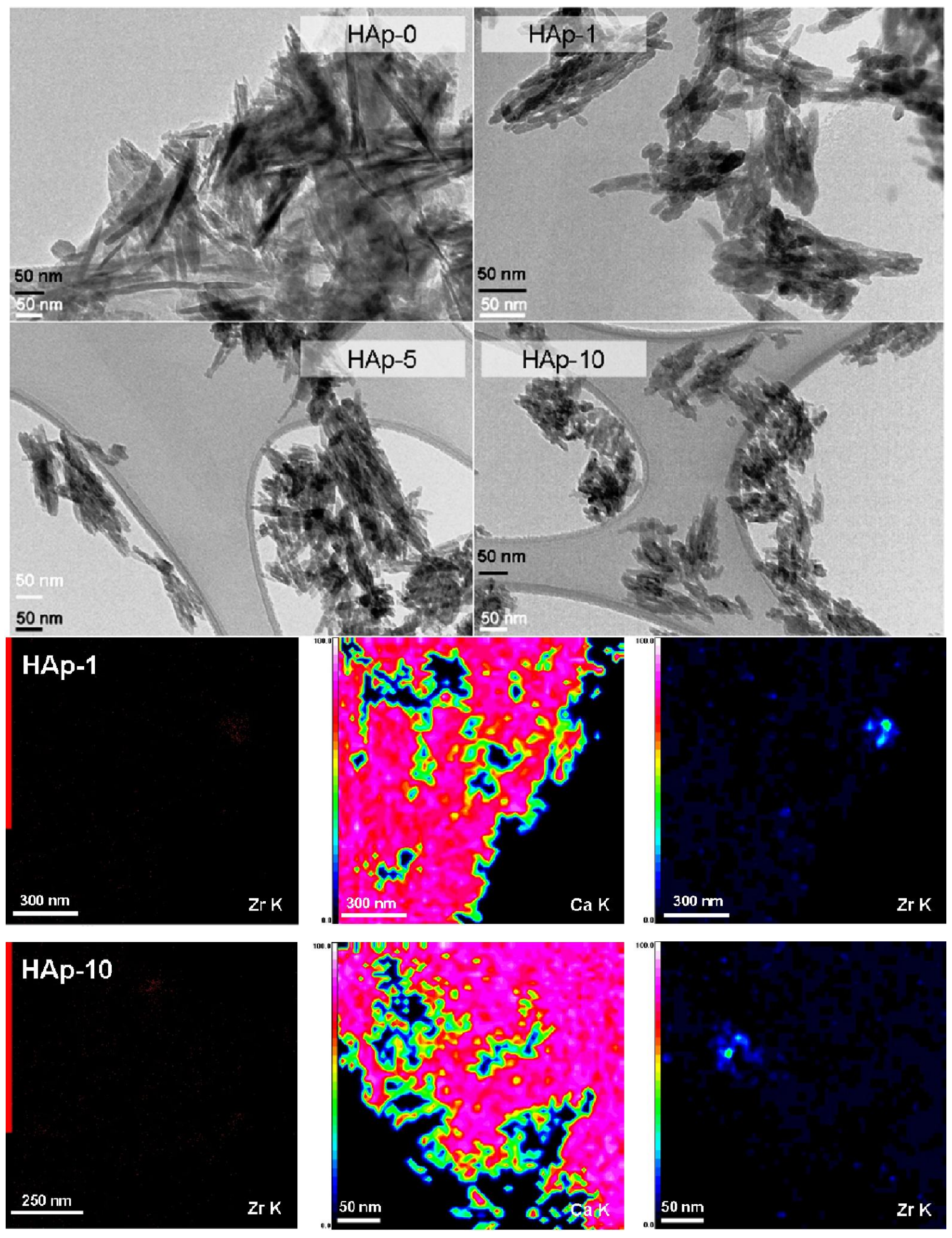


Fig. 3.
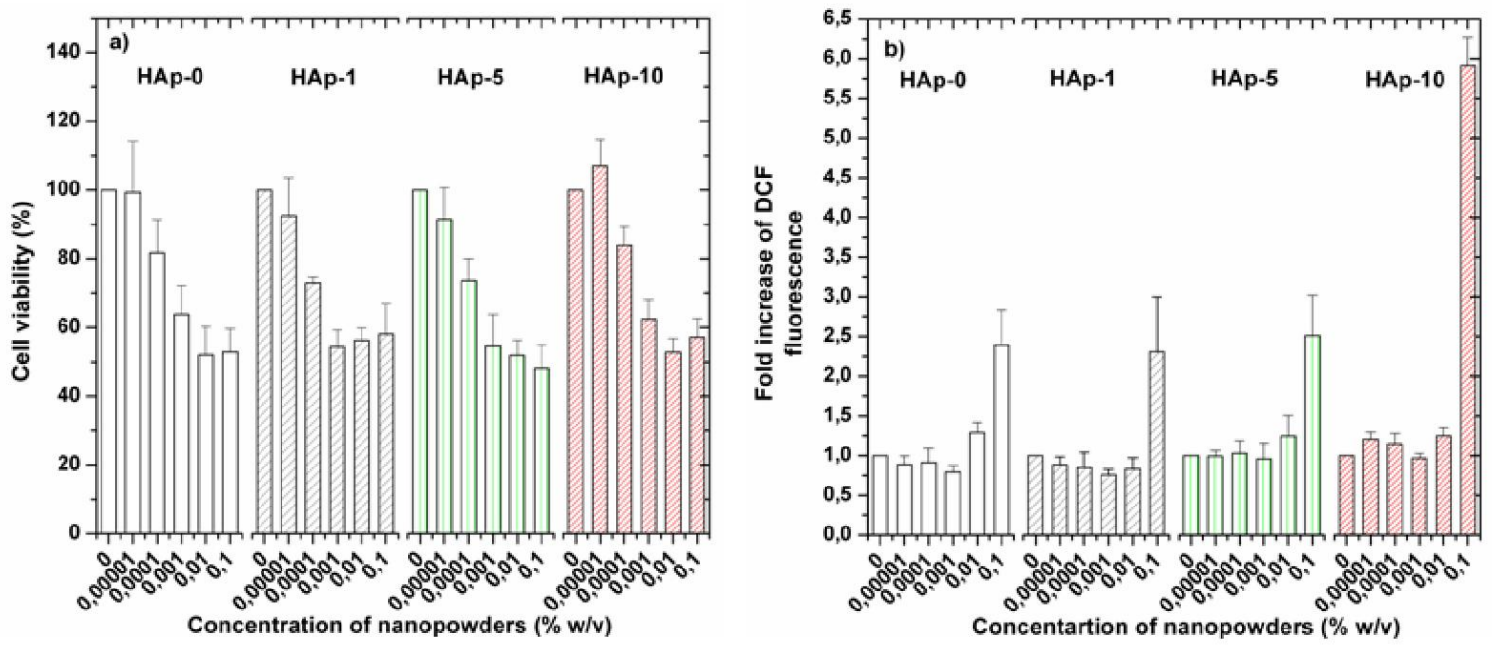
Fig. 4.
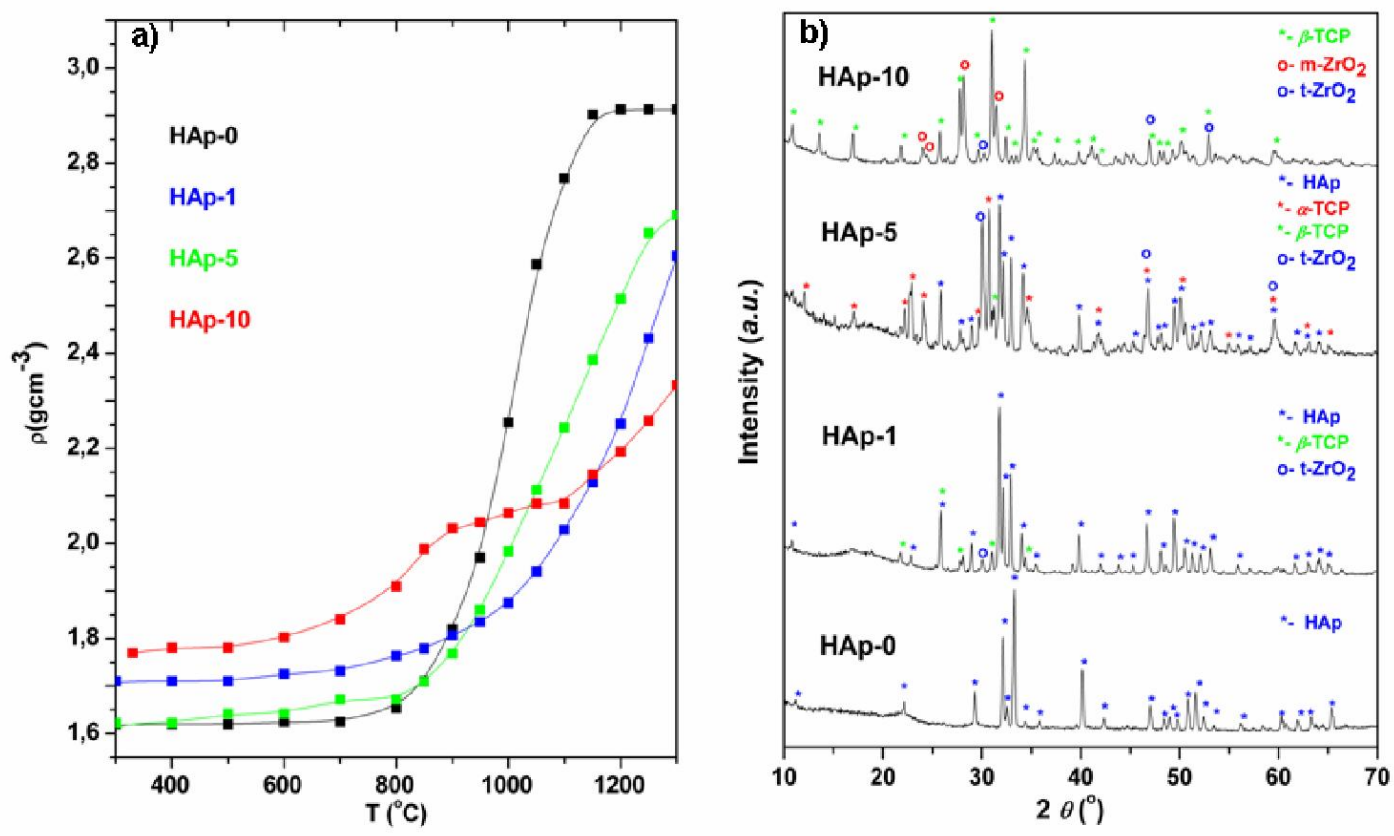